\section{(1) \\ CrossMark}

\title{
Dexmedetomidine versus Propofol in Combination with Fentanyl for Sedation-Analgesia in Colonoscopy Procedures: A Randomized Prospective Study
}

\author{
Elham Kavousi ${ }^{~}$, Hamid Reza Shariefnia ${ }^{1}$, Pejman Pourfakhr ${ }^{1}$, Mohamadreza Khajavi ${ }^{1}$, \\ Alireza Behseresht ${ }^{1, *}$
}

1. Department of Anesthesiology, Sina Hospital, Tehran University of Medical Sciences, Tehran, Iran

* Corresponding Author:

Alireza Behseresht, MD

Address : Department of Anesthesiol-

ogy, Sina Hospital, Tehran University of

Medical Sciences, Tehran, Iran

Telefax : + 982166348522

E-mail: behseresht65@yahoo.com

Received : 15 Oct. 2020

Accepted : 03 Mar. 2021

\section{ABSTRACT}

\section{BACKGROUND}

Colonoscopy is an uncomfortable and short procedure needing brief sedation with fast emergence.

\section{METHODS}

This research is going to measure intravenous dexmedetomidine against propofol-fentanyl combination in terms of sedation-analgesia and hemodynamic changes in non-obligatory colonoscopy procedures. 70 colonoscopy candidates aged between 20 to 70 years were enrolled in this study while separated into two random equal-sized groups ( $\mathrm{p}$ stands for propofol- \& D stands for dexmedetomidine groups). All patients were premedicated with 0.03 $\mathrm{mg} / \mathrm{kg}$ midazolam and $1 \mu / \mathrm{kg}$ fentanyl, 10 minutes and 5 minutes before the colonoscopy process, respectively. $0.5-1 \mathrm{mg} / \mathrm{kg}$ propofol for the P group and $1 \mu / \mathrm{kg}$ dexmedetomidine for the $\mathrm{D}$ group were infused in one minute before the initiation of the procedure following by normal saline as maintenance liquid and boluses of 25-50 $\mu \mathrm{g}$ fentanyl as needed.

\section{RESULTS}

These variables were entered into a datasheet: hemodynamic changes, sedation-analgesia level throughout the procedure, and patients' and physicians' contentment. The mean arterial pressure changes were similar and insignificant in the two groups $(82.44 \pm 12.34$ vs. $87.63 \pm 22.45 p=0.2$ ). The $\mathrm{D}$ group had lower heart rates in comparison with the $\mathrm{P}$ group ( $72.51 \pm 16.7$ vs. $81.56 \pm 15.71 p=0.001)$. The $\mathrm{P}$ group was deeply to moderately sedated and required a significantly lower doses of fentanyl rescue treatment $(71.02 \pm 25.63 \mathrm{vs}$. $91.45 \pm 38.62 \mu \mathrm{g} p=0.003)$. The $\mathrm{P}$ group was associated with a high incidence of apnea and was significantly superior to the D group in the matter of satisfaction ( $43 \%$ against $77 \%$ ).

\section{CONCLUSION}

Colonoscopists' contentment rates were identical in both groups. Propofol infusion is more satisfactory yet having more respiratory depression possibility in comparison with dexmedetomidine infusion in colonoscopy candidates.

\section{KEYWORDS:}

Colonoscopy; Contentment; Dexmedetomidine; Propofol; Sedation-analgesia

\section{Please cite this paper as:}

Kavousi E, Shariefnia HR, Pourfakhr P, Khajavi MR, BehsereshtAR. Dexmedetomidine versus Propofol in Combination with Fentanyl for Sedation-Analgesia in Colonoscopy Procedures: A Randomized Prospective Study. Middle East J Dig Dis 2021;13: 328-332. doi: 10.34172/mejdd.2021.242. 


\section{INTRODUCTION}

Pliable colonoscopy is a widely applied procedure for either screening-diagnostic or therapeutic purposes. Considering the patients' discomfort and nervousness being added to the painful nature of the procedure, using sedation-analgesia drugs through the procedure seems inevitable. Many anesthetic drugs such as midazolam, propofol, and/or alfentanil or pethidine combinations, $\alpha$-agonists, and neuroleptics are frequently administered for this matter. $1,2,3$

Conscious sedation-analgesia is aimed to comfort the patients with minimal adverse effects, and the ideal method is the one with fast induction and emergence, which preserves respiration and hemodynamics stability. Several regimens of drugs are being used at this time for this purpose. $^{4,5}$

Small doses of propofol infusing alongside slight amounts of opioid and ketamine make the epitome of sedation-analgesia with the least possible adverse respiratory and hemodynamic effects. ${ }^{6}$ Dexmedetomidine is a relatively selective $\alpha 2$ adrenoceptor agonist that has a sedative-analgesic, anxiolytic, and sympatholytic action. ${ }^{7}$ And has been employed for sedation in a variety of nonintubating procedures like colonoscopy, awake carotid endarterectomy, shockwave lithotripsy, and vitreoretinal surgery. ${ }^{8}$ Sympatholytic effects of dexmedetomidine may be responsible for distressing side effects, marked hemodynamic instability, and longsome recovery in some studies like a colonoscopy. ${ }^{9}$ This study was done to illustrate that dexmedetomidine, combined with fentanyl, is riskfree and operational in providing safe sedation for colonoscopy. We compared its impacts on analgesia-sedation and hemodynamic alterations with propofol/fentanyl. And also examined its impact on the colonoscopists' and patients' contentment.

\section{MATERIALS AND METHODS}

Permitted by the Ethics Board Committee of Tehran University of Medical Sciences (TUMS) with ethical approval number: 1396.2762 and also approved by IRCT (Iranian Registry of Clinical Trials) registration number of IRCT20170805035510N4, this interventional, randomized clinical trial was carried out on 70 non-emergent (between 20 to 70 years of age) applicants for a pliable colonoscopy under conscious-sedation and analgesia from march 28, 2018 to February 31, 2019.

The exclusion criteria were the patients suffering from liver or heart failure and also those with longtime consumption of drugs like benzodiazepines, neuroleptics, and anticonvulsants. Those with an allergy to drugs used in the investigation, those undergoing laparotomy surgeries, those with body mass index (BMI) above $35 \mathrm{~kg} / \mathrm{m}^{2}$, and mentally ill patients were excluded either. All candidates were thoroughly informed, and written consents were obtained from them prior to the study.

Patients who met the inclusion criteria ASA I \& II, aged 20-65 years old, were anyhow divided into two groups. A computer-based randomization list was used to assign patients to each one of the two study groups. Dexmedetomidine (D) and propofol (P) groups consisted of 35 subjects each.

The syringes were labeled by a colleague who did not participate in sedating and assessment of the patients. Drug syringes of analogous capacity were chosen and were unbeknown to all the staff (the patients, anesthetists, colonoscopists, and the patients' examiner). All patients were kept under standard monitoring conditions, including $\mathrm{SPO}_{2}$, uninterrupted electrocardiography, and Non Invasive Blood Pressure (NIBP) (checked on 3 minutes intervals), and all the data were collected precisely.

Afterward, an intravenous line was fixed, and a balanced solution such as sodium chloride $0.9 \%$ was initiated. All the patients received supplemental $\mathrm{O}_{2}$ of 4-6 lit/ minute by face-mask during the procedure and were injected $0.03 \mathrm{mg} / \mathrm{kg}$ midazolam 10 minutes prior to the procedure. Both groups received fentanyl $1 \mu / \mathrm{kg}$ five minutes prior to the procedure. The propofol (P) group was administered $0.5-1 \mathrm{mg} / \mathrm{kg}$ of propofol, and the dexmedetomidine (D) group, received $1 \mu / \mathrm{kg}$ of dexmedetomidine one minute prior to the procedure, respectively. The level of sedation was estimated using the Observer Assessment of Alertness/Sedation (OAA/S) Scale at 3-minute intervals during the procedure and also in the recovery room as regards; $1=$ complete quiet/unconscious, $2=$ deeply sedated, $3=$ moderately sedated, $4=$ lightly sedated, and $5=$ not sedated. Intermittent administration of fentanyl (25- 50 $\mu \mathrm{g}$ ) was used whenever the sedation level reached grade three or above. Patients' pain intensity was measured by 
the VAS (visual analog scale) method during the procedure. In the recovery room, the estimation of satisfaction stage for both the patients and the colonoscopy specialists were elicited based on the following categorization: $1=$ no satisfaction, $2=$ low satisfaction, $3=$ =medium satisfaction, $4=$ high satisfaction, and $5=$ full satisfaction.

Adverse outcomes such as nausea, vomiting, significant alterations in systolic blood pressure (BP) \& diastolic $\mathrm{BP}$, heart rate (HR) swings more than $30 \%$ of the primary rate, and apnea episodes lasting more than 30 seconds were meticulously recorded.

\section{Statistical Analysis}

To demonstrate the qualitative-information of the investigation, frequency analysis (by percentage) was employed, and for the quantitative data, the mean (standard deviation) was used. Variables and values were declared in the form of frequencies and percentages. Then $\mathrm{X}^{2}$ test and Fisher's exact test were used to determine the interrelationships and their significance level. To investigate the interaction between the intervention and the qualitative outcomes, Chisquare analysis ( $\mathrm{X}^{2}$ test) was applied.

\section{RESULTS}

70 patients were entered in this study and divided into two equal-sized groups randomly. The average age of the patients was $51.5 \pm 10.8$ years (between 23 to 69 years old). Table 1 contains the demographic information of the study.

Hemodynamic alterations magnitude during the procedure were similar between the two groups, as well as the average of mean arterial pressure (MAP) alterations in the $\mathrm{D}$ group in comparison with the $\mathrm{P}$ group $(82.44 \pm 12.34 \mathrm{vs}$. $87.63 \pm 22.45 p=0.2$ ).

On the subject of heart rate, the D group showed lower quantities during the procedure $(72.51 \pm 16.7 \mathrm{vs}$. $81.56 \pm 15.71 p=0.001)$. Desaturation episodes happened more in the $\mathrm{P}$ group compared with the $\mathrm{D}$ group; therefore three patients in the $\mathrm{P}$ group required bag-mask ventilation assistance during the procedure $(p=0.001)$.

Deep to moderate sedation level was observed in all the subjects in the propofol group during the procedure, and the quantity of fentanyl cumulative dosage, which was used in these patients, was far less than the other
Table 1: Characteristics of included patients and the procedures

\begin{tabular}{cccc}
\hline Variables & Group D & Group P & P \\
\hline Age (mean \pm sd) & $55.8 \pm 12.2$ & $57.5 \pm 12.7$ & 0.24 \\
\hline $\begin{array}{c}\text { Sex (Male/ } \\
\text { female) }\end{array}$ & $15 / 20$ & $18 / 17$ & 0.13 \\
\hline $\begin{array}{c}\text { Mean duration } \\
\text { procedure, min, }\end{array}$ & $9.5 \pm 2.9$ & $8.7 \pm 2.8$ & 0.139 \\
\hline Mean duration & $12.3 \pm 2.9$ & $13 \pm 1.9$ & 0.12 \\
\hline
\end{tabular}

group $(71.02 \pm 25.63$ vs. $91.45 \pm 38.62 \mu \mathrm{g}, p=0.003)$. In the D group we faced with $9 \%$ prevalence of light sedation status; therefore more boluses of fentanyl necessarily were injected during the procedure in this group. According to pain estimation results, considering the VAS score below $4,48 \%$ of the patients in the D group and $41 \%$ of the patients in the $\mathrm{P}$ group had average pain severity score (VAS score) below $4(p=0.5)$.

With regard to satisfaction as an important clinical parameter, $43 \%$ of the patients' satisfaction in the D group versus $77 \%$ of the patients' satisfaction in the $P$ group was noticeable and of the significant value $(p=0.001)$.

Colonoscopists' satisfaction recordings during the procedures displayed equality in both groups, with a complete satisfaction prevalence of $41 \%$.

\section{DISCUSSION}

Colonoscopy is a standard technique for diagnosis, screening, treatment, and follow-up purposes in many colorectal diseases. It is usually a painful and unpleasant procedure. So it demands a proper sedation-analgesia drug combination for utmost pain-free patients' cooperation while avoiding adverse outcomes. This investigation has demonstrated the superiority of propofol-fentanyl drug regimen over dexmedetomidine-fentanyl in desirable qualities such as sedation depth and patients' satisfaction during colonoscopy. Dexmedetomidine is usually administered in the ICU to put the patients under light to moderate sedation state. ${ }^{10}$ It is applicable to induce light sedation during procedures like colonoscopy as well. ${ }^{11}$ Dexmedetomidine can be used as an additive to other tranquilizers, for instance, midazolam, fentanyl, and propofol, to improve anxiolysis and keeping the hemody- 
namic stability by reducing the need of tranquilizers. ${ }^{12}$

The study of $\mathrm{Wu}$ and colleagues was conducted on 60 patients in two equal groups to compare dexmedetomidine and midazolam used for endoscopy. Parameters like $\mathrm{SPO}_{2}, \mathrm{HR}$, MAP, patients' satisfaction estimation, and pain severity index were evaluated in this study. Not to mention, fentanyl boluses were used for both groups besides the primary drugs. The outcomes demonstrated a decline in pain scores and improvement of $\mathrm{SPO}_{2}$ values in the dexmedetomidine group. ${ }^{13}$

In the study of Amri and co-workers, dexmedetomidine $1 \mu \mathrm{g} / \mathrm{kg}$ was administered 10 minutes prior to the procedure, followed by $0.5 \mu \mathrm{g} / \mathrm{kg} /$ hour maintenance infusion. The control group was received fentanyl $0.5 \mu \mathrm{g} / \mathrm{kg}$ 3 minutes prior to the procedure, and boluses of $20 \mathrm{mg}$ propofol were injected afterward if necessary. They eventuated declined pain scores and improved hemodynamic steadiness in the dexmedetomidine group versus the propofol group. ${ }^{14}$

In several studies, unlike our investigation, intravenous infusion of dexmedetomidine was started after a loading dose injection.

The procedure time length in our research was under 10 minutes, and we just injected the loading dose of dexmedetomidine alone; thinking of its pharmacokinetic properties, it has a fast distribution half-life of about six minutes and a short-term span of action. ${ }^{15}$

Patients' satisfaction in the dexmedetomidine group was lower than in the propofol group due to unpleasant colonoscopic pain, so these patients received more fentanyl.

With regard to hemodynamic alterations, outcomes of our research were similar to other studies, expressing that the dexmedetomidine group showed a lower HR than the propofol group. Dexmedetomidine is a potent, selective $\alpha 2$-adrenergic agonist, and it inspires sedation by declining the noradrenergic neurons' activity in the locus ceruleus located in the brainstem, escalating the possibility of bradycardia and hypotension in combination with fentanyl. ${ }^{16}$

Jalowiecki and colleagues have found that administering dexmedetomidine alone is not applicable for conscious sedation in outpatient colonoscopy because repetitive fentanyl injection is needed throughout the procedure. ${ }^{9}$

Propofol, joint with opioids or ketamine, is considered risk-free in colonoscopy with little hemodynamic derangements and superior patients' satisfaction. ${ }^{17,18,19}$ Propofol usage in this research approves this discovery that intravenous bolus injections of propofol-fentanyl regimen can improve patients' satisfaction instead of dexmedetomidine regimen throughout the colonoscopy.

Sedation-analgesia level achieved by propofol-fentanyl administration while maintaining the hemodynamic indices caused more satisfaction and fewer painscores rather than the dexmedetomidine group, although, in the dexmedetomidine group, desaturation episodes were infrequent and needed no invasive intervention by the anesthetist.

\section{ETHICAL APPROVAL}

There is nothing to be declared.

\section{CONFLICT OF INTEREST}

The authors declare no conflict of interest related to this work.

\section{REFERENCES}

1. Padmanabhan U, Leslie K, Eer ASY, Maruff P, Silbert BS. Early cognitive impairment after sedation for colonoscopy: the effect of adding midazolam and/or fentanyl to propofol. Anesth Analg 2009;109:1448-55. doi: 10.1213/ane.0b013e3181a6ad31. Epub 2009 Jul 17.

2. Pourfakhr, P. Nouri, K., Shariefnia, H. R., Moharari, R. S Khajavi, M. R. Dexmedetomidine Versus Ketamine Combined With Fentanyl for Sedation-Analgesia in Colonoscopy Procedures: A Randomized Prospective Study. Acta Medica Iranica, 2019;57: 355-8.

3. Sula H, Domi R, Ohri I, Broqi I, Beqiri A, Gani H. Propofol dexmedetomidine for sedation in colonoscopy: A prospective, domized study: 2AP1-7. Eur J Anaesthesiol 2012;29:32.

4. Rex DK, Petrini JL, Baron TH, Chak A, Cohen J, Deal SE, et al. Quality indicators for colonoscopy. Gastrointest Endosc 2006;63:S16-28. doi: 10.1016/j.gie.2006.02.021.

5. Lichtenstein DR, Jagannath S, Baron TH, Anderson MA, Banerjee S. Standards of Practice Committee of the American Society for Gastrointestinal Endoscopy, et al. Sedation and anesthesia in GI endoscopy. Gastrointest Endosc 2008;68:81526. doi: 10.1016/j.gie.2008.09.029.

6. Aydogmus MT, Türk HS, Oba S, Gokalp O. A comparison of different proportions of a ketamine-propofol mixture administered in a single injection for patients undergoing colonoscopy. Arch Med Sci 2015;11:570-6. doi: 10.5114/aoms.2015.52360. 
7. Weerink MA, Struys MM, Hannivoort LN, Barends CR, Absalom AR, Colin P. Clinical pharmacokinetics and pharmacodynamics of dexmedetomidine. Clin Pharmacokinet 2017 ;56:893-913. doi: 10.1007/s40262-017-0507-7.

8. Shukry M, Miller JA. Update on dexmedetomidine: use in nonintubated patients requiring sedation for surgical procedures. Ther Clin Risk Manag 2010;6:111-21. doi: $10.2147 /$ tcrm.s5374.

9. Jalowiecki P, Rudner R, Gonciarz M, Kawecki P, Petelenz M, Dziurdzik P. Sole use of dexmedetomidine has limited utility for conscious sedation during outpatient colonoscopy. Anesthesiology 2005;103:269-73. doi: 10.1097/00000542-200508000-00009.

10. Pasin L, Greco T, Feltracco P, Vittorio A, Neto CN, Cabrini L, et al. Dexmedetomidine as a sedative agent in critically ill patients: a meta-analysis of randomized controlled trials. PLoS One 2013;8:e82913. doi: 10.1371/ journal.pone.0082913.

11. Paris A, Tonner PH. Dexmedetomidine in anaesthesia. Curr Opin Anaesthesiol 2005;18:412-8. doi: 10.1097/01. aco.0000174958.05383.d5.

12. Giovannitti Jr JA, Thoms SM, Crawford JJ. Alpha-2 adrenergic receptor agonists: a review of current clinical applications. Anesth Prog Spring 2015;62:31-9. doi: 10.2344/0003-3006-62.1.31.

13. Wu W, Chen Q, Zhang LC, Chen WH. Dexmedetomidine versus midazolam for sedation in upper gastrointestinal endoscopy. J Int Med Res 2014;42:516-22. doi: 10.1177/0300060513515437. Epub 2014 Feb 10.

14. Amri P, Nahrini S, Hajian-Tilaki K, Hamidian M, Alipour SF, Hamidi SH, et al. Analgesic Effect and Hemodynamic Changes Due to Dexmedetomidine Versus Fentanyl During Elective Colonoscopy: A Double-Blind Randomized Clinical Trial. Anesth Pain Med 2018;8:e81077. doi: 10.5812/aapm.81077. eCollection 2018 Dec.

15. Precedex(Dexmedetomidine hydrochloride) Drug Information: Clinical Pharmacology-Prescribing Information at RxList”. RxList. Retrieved 2015-11-16.

16. Klamt JG, Vicente WV, Garcia LV, Ferreira CA. Effects of dexmedetomidine-fentanyl infusion on blood pressure and heart rate during cardiac surgery in children. Anesthesiol Res Pract 2010;2010:869049. doi: 10.1155/2010/869049. Epub 2010 Aug 19.

17. Khajavi M, Emami A, Etezadi F, Safari S, Sharifi A, Moharari RS. Conscious sedation and analgesia in colonoscopy: Ketamine/propofol combination has superior patient satisfaction versus fentanyl/propofol. Anesth Pain Med 2013;3:208-13. doi: 10.5812/aapm.9653. Epub 2013 Jul 1.

18. Goudra B, Singh PM, Gouda G, Borle A, Carlin A, Yadwad A. Propofol and non-propofol based sedation for outpatient colonoscopy-prospective comparison of depth of sedation using an EEG based SEDLine monitor. $J$ Clin Monit Comput 2016;30:551-7. doi: 10.1007/s10877015-9769-5. Epub 2015 Sep 12.
Baker FA, Mari A, Aamarney K, Hakeem AR, Ovadia B, Kopelman Y. Propofol sedation in colonoscopy: from satisfied patients to improved quality indicators. Clin Exp Gastroenterol 2019;12:105-110. doi: 10.2147/CEG.S186393. eCollection 2019. 